\title{
Criminalidad en la Baja Frontera: el caso del antiguo Departamento de Lautaro, 1849-1869
}

\author{
Carlos Ibarra Rebolledo ${ }^{1}$ \\ Recibido: 20 de diciembre de 2013 - Aceptado: 15 de junio de 2014
}

\begin{abstract}
Resumen
A mediados del siglo XIX, la Araucanía comenzaba a enfrentar el interés tanto de empresarios como del Estado de Chile por lograr penetrar cada vez más en territorio mapuche, lo cual implicaba hacer valer su soberanía por medio de la institucionalidad vigente. En este contexto es que uno de los problemas más graves por solucionar fue el desarrollo de la criminalidad en la Baja Frontera, de la cual analizamos la sección costera donde, paralelamente, se estaban dando procesos modernizadores de corte industrial.
\end{abstract}

Palabras clave: Criminalidad, vida fronteriza, justicia estatal, modernidad.

\section{Criminality in the low border: The case of Lautaro old department, 1849-1869}

\begin{abstract}
In the mid-Nineteenth Century, the Araucania began to face the interests of entrepreneurs and the State of Chile for penetrating deeper in Mapuche territory, which meant to assert their sovereignty through existing institutions. In this context, one of the most serious problems to solve was the development of criminality in the low border. We analyze the coastal section where parallel modernizing processes of industrial nature were occurring.
\end{abstract}

Keywords: criminality, border life, State justice, modernity.

Chileno. Profesor de Historia y Geografía, Universidad de Concepción, y Magíster en Historia, Universidad de Chile. Actualmente es académico en la Universidad San Sebastián. E-Mail: cibarra@udec.cl 


\title{
Criminalidade no baixo da fronteira: o caso do antigo departamento de Lautaro, 1849-1869
}

\begin{abstract}
Resumo
A meados do século XIX, Araucanía estava começando a enfrentar o interesse tanto de empresários como do Estado do Chile por lograr penetrar cada vez mais no território mapuche, que significava fazer valer sua soberania por meio da institucionalidade vigente. Neste contexto, é que um dos maiores problemas por resolver foi o desenvolvimento da criminalidade Baixa Fronteira, da qual analisamos a seção costeira onde, ao mesmo tempo, estavam se dando processos modernizadores de corte industrial.
\end{abstract}

Palavras-chave: Criminalidade, Vida de Fronteira, Justiça Estatal, Modernidade.

La zona denominada como Frontera en el sur de Chile a mediados del siglo XIX, abarca un espacio geográfico bastante amplio, ya que involucra los poblados allende el Biobío (Baja Frontera) y aquellos situados en las regiones meridionales que conocemos como Alta Frontera o Araucanía (véase figura 1). Fueron los habitantes de estas áreas (mapuches en su mayoría) los que ya desde el siglo XVII y, más aún, a inicios del siglo XIX, comenzaron a ser testigos de la llegada cada vez más masiva de sujetos que huían de la guerra de independencia y de la guerra a muerte, procedentes de la zona central de Chile, situación que se mantuvo durante décadas (Góngora, 1966; Ortega, 1992). Consecuentemente, se generó un ambiente de rebeldía social protagonizado por estas personas en la Araucanía, para los cuales la ley del Estado tenía una importancia prácticamente nula, lo que dio cabida a una serie de situaciones que a ojos de los agentes del poder central violaban el estado de derecho de la República, problema que intentó ser corregido a través de la instalación de juzgados, tribunales y agentes del orden (guardias cívicas, policías) en aquellos poblados donde existían autoridades chilenas como, por ejemplo, en las villas situadas anexas a los fuertes de la Frontera, como Santa Juana o Negrete. Este ambiente desató una lucha por imponer -de parte del Estado de Chilenuevas normas, lo que requería -teóricamente- la obediencia a ellas de parte de aquellos/as que habían llegado a esas zonas rehuyendo el peso de las leyes chilenas y que vivían según sus propias costumbres y reglas consuetudinarias. La cuestión no era fácil de lograr, había que derribar la existencia de un particular estilo de vida de tipo fronterizo, donde la transgresión y la violencia eran pan de cada día, situaciones evidenciadas por los estudios de varios historiadores nacionales enfocados sobre todo en las zonas de la Araucanía interior ( $\mathrm{v}$. gr. León, L., 2005; Parentini, 2003; Pinto, J., 1985).

Lo que proponemos en este artículo es reforzar esa visión tomando el caso de la zona costera de la Frontera entre los años 1849 y 1869, toda vez que la mayor parte de los estudios sobre violencia en la Araucanía se concentran 
en la región de la Alta y la Baja Frontera interior y no en la costera. Además, pretendemos dar cuenta del deficiente accionar de la institucionalidad que tuvo como misión frenar la criminalidad en la costa de la Araucanía, fenómeno que tuvo un doble protagonismo en las áreas rurales aledañas a la villa de Santa Juana de una parte y, cada vez más, en las nacientes villas minero-carboníferas de Coronel y Lota. Cabe señalar también que sólo al final del período en estudio otro protagonista entró en escena, el Ejército dirigido por Cornelio Saavedra, el que, sin embargo, concentró sus fuerzas y accionar en la zona de Lebu al interior de la Araucanía (la llamada Línea del Malleco).

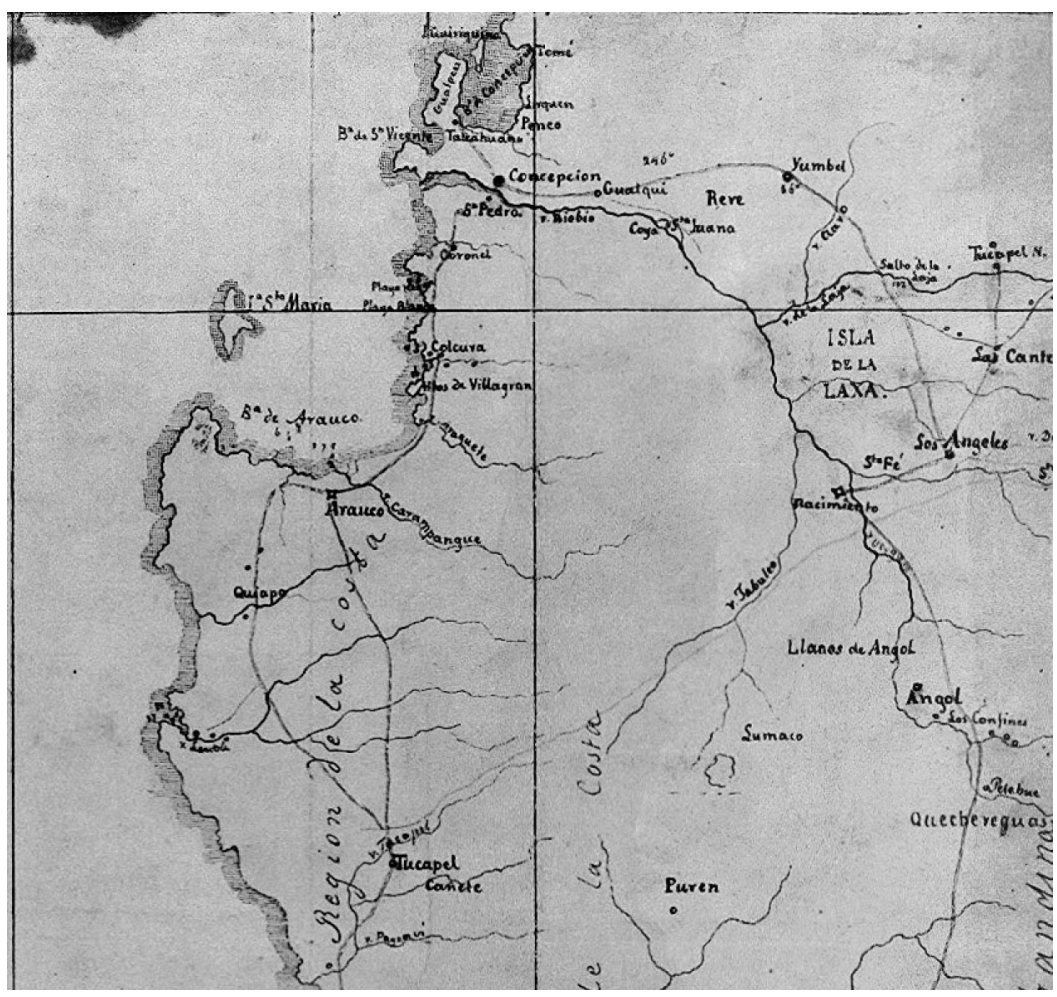

Figura 1 Gay, Claudio (1845). Bosquejo de un mapa de la Araucanía (detalle).

\section{Antecedentes generales del Departamento de Lautaro, 1849 - 1869}

\section{a. Evolución político-administrativa del territorio}

El departamento de Lautaro en el período que aquí se estudia, era parte de la provincia de Concepción, y estaba situado al sur del río Biobío, dentro del 
territorio que ha venido a denominarse como la Baja Frontera. Comprendía originalmente (es decir, entre 1826 y 1852), las villas de Santa Juana, Arauco y Nacimiento y los villorrios de Lota, Colcura y San Pedro². En 1852 el gobierno central decidió segregar a Arauco y Nacimiento, que pasaron a formar parte de los departamentos de Arauco y Biobío respectivamente 3 . Desde entonces, los límites político-administrativos se mantuvieron inalterados (véase figura 2). En 1927 se le hizo un cambio de nombre cuando el departamento de Lautaro allende el Biobío pasó a llamarse departamento de Coronel, legando su antigua denominación a una nueva división político-administrativa ubicada en la entonces provincia de Cautín ${ }^{4}$.

2 Todos estos lugares correspondían a los nombres y ubicación de antiguos fuertes coloniales establecidos allí desde el siglo XVII. De hecho, la idea original que impulsó el gobierno central hacia 1823 comprendía la creación de una división territorial al sur del río Biobío, por la costa, que incorporaba a los antiguos fuertes ya mencionados, área a la que se denominaría como departamento de Lautaro (antiguo Partido de Lautaro), obviamente en honor del cacique mapuche de siglo XVI. Véanse "Lei de demarcación política". En Sesiones de los cuerpos lejislativos de la república de Chile (1826), sesión № 52 del 26 de agosto de 1826. Santiago de Chile. pp. 423-424. También "División administrativa del Estado de Chile de 1823 dirijida a la Intendencia de Coquimbo". En: http://www.educarchile.cl/Portal. Base/Web/verContenido.aspx?ID=138529 (revisado el 30 de marzo de 2013). También en Asta-buruaga [sic], Francisco (1867), Diccionario Jeográfico de la república de Chile, D. Appleton \& Cia., New York, USA.

3 Santa Juana sucedió a Colcura como cabecera departamental en 1841. Colcura, a su vez, lo había sido entre 1826 y 1841 . El terremoto de 1835 terminó arruinando el poblado del antiguo fuerte de San Miguel Arcángel de Colcura (su nombre original) con lo que se decidió trasladar la cabecera a la villa de Santa Juana de Guadalcázar. En 1865, Coronel pasó a ser la nueva cabecera departamental.

4 DFL 8.582/1927, arto. 2, núm. 30 y 36. Esta nueva modificación político-administrativa, fusionó los antiguos departamentos de Arauco y Lautaro, unión a la cual se denominó como departamento de Coronel. 


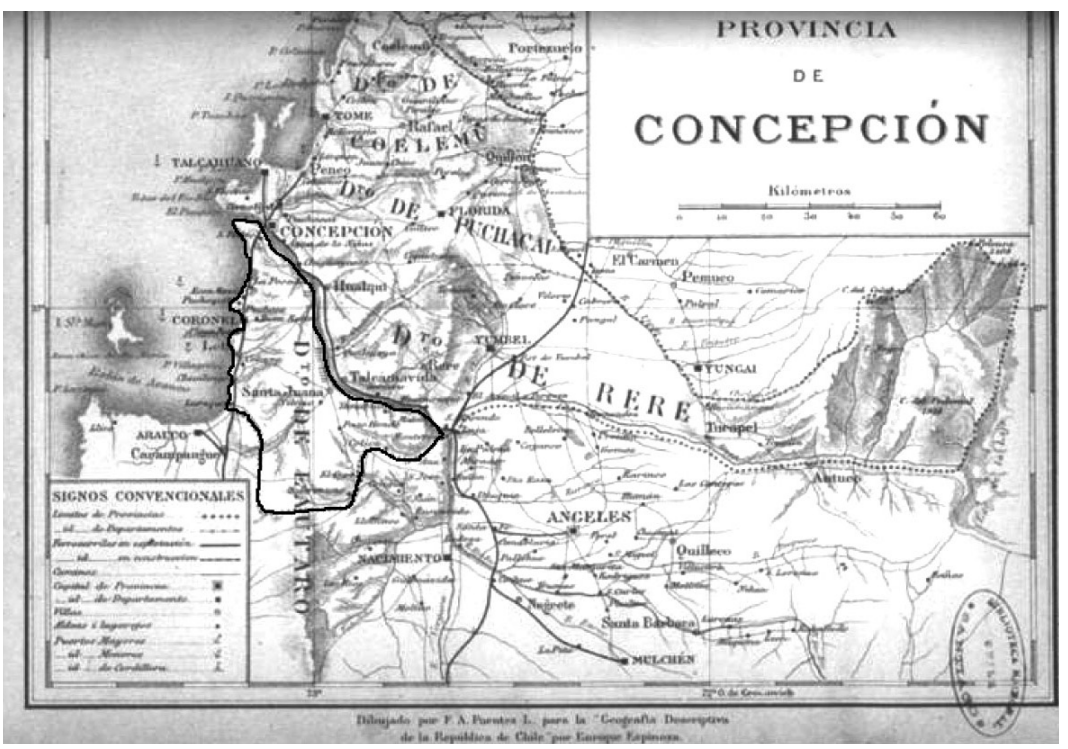

Figura 2 Espinoza, Enrique (1907). Provincia de Concepción. En este mapa hemos destacado el área que comprendía el departamento de Lautaro.

\section{b. Desarrollo económico}

La economía departamental tuvo su base en la actividad agro-ganadera, como se confirma de la lectura de los informes mensuales enviados por los gobernadores al Intendente de la provincia de Concepción, donde se daba detallada cuenta de los precios de los principales productos que daban vida al circuito mercantil de esta parte de la Frontera5 ${ }^{5}$. Esta situación se mantuvo hasta mediados de la década de 1850, cuando la explotación del carbón en Coronel y Lota comenzó a cobrar su cuota de protagonismo afectando aspectos relevantes de la vida económica de la zona, como la disponibilidad de mano de obra. Así, por ejemplo, el periódico penquista El Correo del Sur señalaba en 1855 la cada vez más frecuente fuga de inquilinos hacia los centros minero-carboníferos de Coronel y Lota mientras que, en contraparte, durante la época de las cosechas los dueños de los minerales de carbón se quejaban de la huida de trabajadores hacia los campos, por lo que pidieron al gobierno provincial:

"Ordenar a los licitadores de los pasajes del [río] Biobío correspondientes a es[t]a provincia [de Concepción] (...) que no permitan pasar de

5 Cfr. "Copiador de oficios enviados por la gobernación [de Lautaro] a la Intendencia de Concepción". En: Archivo Nacional, fondo Gobernación de Lautaro, vol. 2, 1842 - 1861. 
una a otra parte a ninguno de los trabajadores ocupados en las minas [de carbón] si estos no presentan un pasaporte dado por el Inspector o subdelegado o dueño del establecimiento donde hubieren trabajado, para evitar de este modo que se fuguen llevándose el dinero anticipado que hubiesen recibido" (El Correo del Sur, Concepción, 28-VI-1855).

Eran las primeras medidas que buscaban la proletarización de los trabajadores del carbón a través del control de su movilidad espacial ${ }^{6}$.

Es importante mencionar que para mediados de la década de 1850 se informaba que sólo en Coronel se ocupaban 370 hombres para las minas de carbón (El Correo del Sur, Concepción, 28-VI-1855). Si a ello sumamos los centenares de personas que laboraban en los piques de los Cousiño, Rojas, Alemparte, Délano y Schwager (por mencionar a las minas más importantes), la cantidad sobrepasaba con creces las mil almas, número que fue en aumento, atraído sobre todo por la idea de obtener un jornal por su trabajo ${ }^{7}$. Ello explica que entre 1852 y 1870 se haya pasado de una producción de poco más de seis mil cuatrocientas toneladas anuales de carbón en el primer año a más de doscientas cincuenta mil en el último (Ortega, 2005: 232, 234).

\section{c. Evolución demográfica}

En cuanto a la población del departamento, según los datos entregados por los distintos censos realizados en la zona, la población aumentó en forma lenta pero progresiva. Según un informe de 1847 (publicado en 1850) existía un total de 13.843 habitantes (Oficina de Estadísticas, 1850:71), número que en el censo de 1854 subió a $15.350^{8}$. Once años después contaba con 29.477 habitantes, es decir, 14.127 personas más -ello pese a las segregaciones

6 Sobre la proletarización véanse, como bibliografía básica, los textos de Gabriel Salazar (2000), Labradores, peones y proletarios; de Gabriel Salazar y Julio Pinto, Historia Contemporánea de Chile (1999), vol. II; de Sergio Grez Toso (2007), De la regeneración del pueblo a la huelga general. Sobre la transformación específica del campesino en minero carbonífero véase el texto de Luis Ortega (1992), "La frontera carbonífera", en: Mapocho, № 31, pp. 131 - 148. También toca brevemente el tema el texto de Leonardo León (2005), Araucanía: la violencia mestiza y el mito de la "pacificación", 1880 - 1900 (para fines del siglo XIX).

7 En el mismo artículo señalado en la cita anterior, el reportero agregaba: "Hay más labores todavía, pero no las he apuntado porque desconozco su estado y veo con placer que aumentan todos los días luego que se presentan trabajadores del campo pues lo que faltan no son minas sino brazos". Ídem.

8 Según José María Avello, gobernador de Lautaro, la población del departamento en 1854 era de 15.399 personas. Véase oficio № 74, Santa Juana, 25 de mayo de 1854. En: Gobernación de Lautaro, vol. 2, "Copiador de oficios enviados por la gobernación [de Lautaro] a la Intendencia de Concepción", s/f. 
territoriales de 1852 (Censo de 1865, 1865:63)- lo que se explicaría por las migraciones, fenómeno que se desarrollaba desde los albores de la era republicana y que la apertura de los minerales de carbón de Lota y Coronel aumentó significativamente (Guevara, 1903:215) ${ }^{10}$. Un ejemplo del protagonismo de la minería del carbón como imán laboral es evidenciado en un oficio enviado por José María Avello -gobernador de Lautaro- al Intendente de Concepción en 1854):

"Dificil ha sido en este departamento conseguir el enganche de peones para los travajos del camino del Tomé a Chillán, porque a mas de ser escasos se ocupan en su mayor parte en las minas de carvon de Lota i Coronel. Conbensido de que todo esfuerzo es inútil doi cuenta a Us. del ningun resultado favorable que ha dado la comisión que Us. me confiere"11.

Cabe señalar que las migraciones fueron un elemento importante que en parte permiten entender el accionar de los sujetos que cometieron delitos en las tierras allende el Biobío, sobre todo en aquellos poblados donde abundaba el ganado -como en Santa Juana- o en los lugares donde nacían nuevas villas -como Coronel y Lota-vistas como verdaderas fuentes de recursos para muchos de los migrantes, entre los cuales cientos venían de enfrentar años difíciles desde sus zonas de origen (Salazar, 2001). Se ha demostrado que la mayoría de los migrantes procedían de la provincia del Ñuble (Ortega, 1992: 131-148; Brito y Vivallos, 2010: 53-71).

Por nuestra parte, en este aspecto hemos querido aportar con los nuevos datos gracias a los cuales hemos podido llegar a algunas cifras que confirman las conclusiones de los historiadores ya mencionados ${ }^{12}$. A saber, 29 de 44 reos procesados durante el período 1849 - 1869 señalaron su procedencia como local (nacieron en el departamento de Lautaro), a la vez que 15 de ellos indicaron que eran naturales de otros departamentos, particularmente de sectores como Curapeumo (cerca de Parral), Quirihue, Yungay, Tomé, Penco, Talcamávida, Quilacoya, San Carlos y Hualqui. El número de procesados que señalaban su procedencia como de fuera de las villas del departamento de Lautaro aumentó con el paso del tiempo (Ibarra, 2010: 54-62).

9 Según el análisis de dicho censo, ello significó un aumento de su población intercensal (1854 - 1865) de un $92 \%$.

10 Las tierras de La Frontera "desde [Vicente] Benavides [han] sido el obligado asilo de todos los revolucionarios".

11 Gobernador de Lautaro al Intendente de Concepción. Santa Juana, 1 de agosto de 1854 En: Gobernación de Lautaro, volumen 2, s/f.

12 Los nuevos datos a los cuales hacemos referencia se componen de una serie de piezas judiciales encontradas el año 2008 en el Juzgado de Letras de Coronel en el contexto de la elaboración de la tesis de magíster del autor. 
Hubo también un aporte no menor de inmigrantes extranjeros, casi todos asentados en las villas donde se explotaba el carbón, siendo la cantidad más significativa para la época en estudio los procedentes de Escocia que habían sido contratados por Matías Cousiño en 1854 (Mazzei, 1999: 85-128). Paralelamente, se sumaron ingleses, italianos, alemanes, franceses, españoles, daneses, etc., algunos de los cuales también fueron alcanzados por el brazo de la justicia criminal13.

Cabe señalar que el contexto en la zona conocida hoy como "del carbón" era, a mediados del siglo XIX, bastante especial. Y es que siguiendo órdenes del gobierno central, el Intendente de Concepción Rafael Sotomayor Baeza fundó entre 1854 y 1855 dos nuevas villas, Coronel y Lota, lugares establecidos para hacer frente a la demanda de tierras y casas como consecuencia de la apertura de minerales de carbón de distinto calado (piques, labores, minas). Los informes de la época señalan que la creación de ambas ciudades iba a la par con el interés de nuevos propietarios foráneos. Por ejemplo, en 1854 en el poblado de Lota, las manzanas centrales estaban "ocupadas" (vendidas) por lo que, según Sotomayor, se debió ampliar el centro de las misma.

Con la fundación de estos nuevos poblados, el Estado de Chile ganaba presencia en una zona que estaba considerada a la fecha como parte integral de la Araucanía "salvaje" o "incivilizada", por lo que el avance de la "civilización y de la industria" sería -en el discurso progresista de la época- un gran aporte al desarrollo local y nacional. Es lógico pensar en este sentido que uno de los elementos que debía controlarse por medio de los agentes del Estado era la criminalidad.

\section{Factores que facilitaron el desarrollo de la criminalidad en el departamento de Lautaro}

Conocidos son ya los estudios en torno a la vida fronteriza de mediados y fines del siglo XIX en la conflictiva zona de la Araucanía interior ( $v$. gr. Pinto, 1985; León León, 2001; León, 2005). La mayor parte de los problemas que existían en estos últimos se originaban en cuestiones de presupuesto y en la falta de financiamiento para adquirir armas, pagar los sueldos, mejorar

13 En los libros de la parroquia San Pedro de Coronel conservados en el Archivo Notarial del Arzobispado de Concepción, existe un cuadernillo titulado "Libro de matrimonio[s] de disidentes", donde es posible leer la procedencia de los novios, todos extranjeros y de las más diversas nacionalidades. Estas parejas al momento del casamiento profesaban una religión no católica, pero aceptaban casarse bajo el amparo de ésta. Ello es una muestra más del fenómeno que describimos. 
la infraestructura, entre otros ítems. Agréguese a lo anterior la falta de una formación profesional del personal carcelario, el que en ocasiones permitió e incluso ayudó a la fuga de los reos, lo que no venía sino a empeorar la cuestión penitenciaria en una zona que durante el período estudiado debió enfrentar la catástrofe creada por dos guerras civiles (1851 y 1859) además de la permanente tensión entre el mundo mapuche y el chileno (v. gr. Guevara, 1903: 175 - 256). Veamos el detalle de algunos de estos factores en la zona fronteriza costera.

\section{a. El problema de la infraestructura carcelaria}

El Estado de Chile, en su afán por imponerse en una de las zonas más conflictivas y problemáticas del país, inició en los albores de la república (1826) un plan de incorporación de dichos territorios por medio de sus agentes institucionales. A la existencia de gobernadores, subdelegados e inspectores, en 1849 se sumó la instalación de un Juzgado de Primera Instancia en el departamento de Lautaro con sede en Santa Juana (cabecera departamental) con el fin de menguar la crecida demanda de juicios existente en los tribunales de Concepción, los que hasta esa fecha debían recibir las causas judiciales del departamento lautarino. Ello permitiría -en la visión del gobierno central- consolidar la presencia de la justicia estatal en una tierra donde, básicamente, primaban las leyes consuetudinarias creadas por la tradición de la vida fronteriza. Para reforzar la preminencia judicial chilena se instaló también una cárcel. Hasta aquí todo parecía ir por el camino correcto.

Sin embargo, los informes de los gobernadores daban cuenta de un panorama menos positivo. En reiteradas ocasiones, especialmente durante la década de 1850, los reclamos por la situación carcelaria abundaban. Un oficio enviado desde Santa Juana en 1854 señalaba:

"En una sola pieza de ciete varas [5,6 metros] en cuadro i tres seldas pequeñas para incomunicados de que se compone la cársel de esta villa cavecera no pueden estar ni lijeramente acomodados veintidos presos que se encuentran en ella $(\ldots)^{\prime 14}$.

A inicios del año 1855, se notificó la inversión de $\$ 200$ en un edificio para cárcel (cuya construcción estaba planificada desde 1849)15, monto insuficiente según se advierte de los reiterados reclamos del gobernador José María Avello:

14 Oficio del gobernador de Lautaro al Intendente de Concepción, Santa Juana, 15 de mayo de 1854, s/f. En: Gobernación de Lautaro, volumen 2.

15 Oficio del gobernador de Lautaro al Intendente de Concepción, Santa Juana, 14 de enero de 1855, s/f. En: Ibídem. 
"Una de las principales necesidades que mas se hase sentir en la cavesera de este Departamento es, la falta de un edificio adecuado para carcel i que presente alguna lijera comodidad para el precidio, pues no se le puede dar el nombre de tal a una sola pieza de ciete varas en cuadro i tres pequeñas seldas de dos varas de ancho $[1,6$ metros] i cuatro de largo [3,2 metros] que sirve actualmente" ${ }^{\prime 16}$.

Avello alegaba sobre todo por las insalubres condiciones en las cuales se encontraban los reos en una cárcel que, en realidad, era una casa particular arrendada por el municipio local. Por ello, ese año se presentó -nuevamente- un proyecto de cárcel para Santa Juana. Pero en 1858 la situación no se había alterado:

"No es posible contener en una reducida piesa i uno que otro cuarto pequeño el grueso de mas de treinta presos de uno i otro sexo. La autoridad llega a ser impotente porque en vista de tanta estreches hai que desentenderse de muchas faltas por no tener que amontonar hombres i mujeres en un recinto demasiado recargado" 17 .

Peor efecto tuvo la Guerra Civil de 1859 en aspectos tan puntuales como las visitas. Refiriéndose a aquello, el gobernador Avello exponía que en el primer y segundo trimestre de 1859 "se ha dejado de hacer varias visitas [a la cárcel] por causa de la revolución. [Y] es que hallándome todo esto en completo desorden no era dado contraerse a llenar dicho deber" 18 .

Frente a esta realidad penitenciaria, no cabe duda de que la delincuencia se veía facilitada, en especial en los campos, donde la mayor cantidad de delitos correspondía al robo de animales (abigeato) como lo señalaba el mismo gobernador Avello en 1855:

"Cada vez mas se deja sentir en este departamento el urto de ganados mayores en que la poca vijilancia de las autoridades parece ser el principal motivo para que siga adelante un mal tan perjudicial al vesindario y a la moral misma" ${ }^{\prime \prime}$.

La realidad carcelaria de la Araucanía, aún bien entrado el siglo XIX, estaba en muy mal pie, las autoridades eran incapaces de enfrentar estos problemas

16 Oficio del gobernador de Lautaro al Intendente de Concepción, Santa Juana, 22 de mayo de 1855, s/f. En: Ibídem.

17 Oficio del gobernador de Lautaro al Intendente de Concepción, Santa Juana, 17 de mayo de 1858, s/f. En: Ibidem.

18 Oficio del gobernador de Lautaro al Intendente de Concepción, Santa Juana, 11 de julio de 1859, s/f. En: Ibídem.

19 Auto cabeza de proceso, Santa Juana, 23 de marzo de 1855, f. 1. En: "Causa por sospechas de abigeato contra Juan de Dios Medina", Archivo Judicial de Coronel. 
y los centros penitenciarios -si es que pueden llamárseles así- no podían absorber la demanda de presos que se generaba a diario en estas tierras por causas que, como se ha visto, muchas veces eran culpa del mismo sistema carcelario fronterizo. Esta situación se mantuvo en el tiempo y vino a unirse a la misma realidad vivida por las cárceles de los nuevos poblados que se iban fundando a medida que el avance del ejército chileno y las autoridades estatales incorporaban más territorios bajo la administración chilena (León León, M., 2001).

\section{b. Disponibilidad de guardias y policías}

Otro aspecto no menor, era el de la vigilancia de las cárceles. Cada cierto tiempo, estas eran testigo de la fuga de presos muchas veces por las malas condiciones de los recintos carcelarios, lo que terminaba minando el intento de las autoridades por detener y castigar a los infractores de la ley. Es frecuente encontrar noticias sobre fugas como consecuencia, además, de la mala formación de los guardias cívicos que estaban al cuidado de los presos, así como de la connivencia e incluso de la corrupción de aquellos. Los informes a la intendencia desde la gobernación eran claros en este aspecto. En 1852 se señalaba que:

"La guardia que custodia la carsel de este pueblo [de Santa Juana] no es vastante para mantener en seguro al precidio porque [se compone] (...) del miserable numero de un cavo i tres soldados, son cívicos i caresen por lo mismo de aquella perisia militar tan necesaria i vemos que suceden fugas con frecuencia" 20 .

A las necesidades materiales, y como se señaló anteriormente, se sumaba la impericia de sus vigilantes:

"A más de ser [guardias] cívicos el mal estado del armamento i la carencia de municiones no da seguridad ni a sus propias personas. (...) Se llega a temer que de noche i aun de dia, forsando la pequeña guardia invadan i cometan desorden en algunas casas poco favorecidas para proporcionarse recursos en su fuga"21.

Este tipo de informes hacían que las peticiones para aumentar el número de guardias y para mejorar la calidad del armamento se transformasen en una constante. En 1854 el Gobernador pidió al Intendente de Concepción que se

20 Oficio del Gobernador de Lautaro al Intendente de Concepción, Santa Juana, 27 de noviembre de 1852, s/f. En: Gobernación de Lautaro, volumen 2.

21 Oficio del Gobernador de Lautaro al Intendente de Concepción, Santa Juana, 25 de julio de 1853, s/f. En: Ibídem. 
aceptase el traslado de algunos reos a esa ciudad por encontrarse la de Santa Juana mal habida, mal vigilada y hacinada, situación que se reiteró varias veces $^{22}$. Esta realidad ayudó a que las fugas fuesen habituales aprovechándose de oportunidades tales como los traslados y de la pésima vigilancia ${ }^{23}$ :

"Anoche han fugado de la carsel de este pueblo [de Santa Juana] Pedro Dias i Bernardo Admestias con determinacion sin duda de pasarse para el otro lado del Bio bio por ser el primero del Departamento de Chillan (...). Sin perdida de tiempo debe U[sted] prevenir a los dueños de los pasajes i Jueses de la Subdelegacion de su mando para que luego que tengan noticia de los profugos procuren tomarlos pricioneros i remitirlos con la correspondiente Custodia a esta Cavesera"24.

Informaciones de este tipo hacían que la sensación de inseguridad estuviera presente en las tres principales villas del departamento -Santa Juana, Coronel y Lota- desde donde se pedía al gobernador que aumentase la dotación de la policía urbana (1857) ${ }^{25}$, dado que en el caso de estos dos últimos poblados, si bien contaban con la policía de los establecimientos carboníferos, eran de carácter privado ${ }^{26}$, lo que no garantizaba un accionar más efectivo.

Otro ejemplo de las fugas y del descuido policial es el siguiente parte enviado al Juez de Primera Instancia del departamento:

"Doi parte al S[eñ]or Juez de $1^{\text {a }}$ |[nstancia] de haberse fugado de la carcel el reo Juan de Dios Gonzalez hayer a la oracion por descuido del cabo de guardia i el sentinela i ninguno de los dos saben por donde puedan haberse salido este reo" 27 .

22 Oficio del gobernador de Lautaro al Intendente de Concepción, Santa Juana, 15 de mayo de 1854, sin foja. En: Ibídem.

23 Cabe hacer notar que en contraparte, el sistema judicial castigaba duramente las fugas de la cárcel así como la negativa a presentarse a declarar voluntariamente (según la jerga judicial ello hacía caer a los prófugos en rebeldía y contumacia). Fue el caso de Raimundo Soto y Cipriano Peso, quienes tras haberse escapado de su traslado desde Talcamávida a la cárcel de Santa Juana y terminar siendo nuevamente capturados, fueron condenados -por el intento de fuga- a 50 y 100 azotes, respectivamente, por su rebeldía y contumacia (v. Sentencia del caso, Santa Juana, 15 de octubre de 1856, fs. 34 - 34v. En: "Causa por abigeato, contra Raimundo Soto, José Manuel Fuentes y Cipriano Peso", Archivo Judicial de Coronel). Misma pena de 50 azotes tenía el delito de reincidencia (v. "Causa por abigeato contra José Francisco Salazar, José Mieres y Juan de Dios Arriagada" en Ibídem).

24 Oficio del gobernador de Lautaro al Intendente de Concepción, Santa Juana, 13 de abril de 1850, s/f. En: Ibídem.

25 Oficio del gobernador de Lautaro al Intendente de Concepción, Santa Juana, 30 de junio de 1857, s/f. En: Gobernación de Lautaro, volumen 2.

26 Oficio del gobernador de Lautaro al Intendente de Concepción, Santa Juana, 14 de junio de 1858, s/f. En: Ibídem.

27 "Causa por hurto, contra Juan de Dios González", Coronel, 6 de agosto de 1870, f. 3. En: Archivo Judicial de Coronel. 
Lógicamente que estas situaciones causaban molestia en las autoridades locales, lo que llevó en más de una oportunidad a elevar airados reclamos a las autoridades competentes, exigiendo o, al menos, pidiendo se cuidase más la vigilancia en las cárceles ya que en ocasiones era inaceptable la reiterada fuga de reos debido a fallas del aparato carcelario:

"Pongo en conocimiento del Señor Juez de primera instancia que ayer veintinueve del corriente [mes de noviembre de 1875] se fugó del trabajo que hace [en] el presidio, el reo prosesado por robo Pedro Gómez cuya fuga la ocasiona el descuido de los custodios por esa confianza que tienen en los reos, confianza que perjudica en sumo grado, ya por la fuga como por las vevidas que se be continuamente" 28 .

Reos fugados, guardias corruptos, un ambiente de confianza y ebriedad que, sin duda, ayudaba sobremanera a la comisión de este tipo de delitos. Lamentablemente, esta realidad no cambió en el corto plazo en la Araucanía sino que, por el contrario, empeoró con los años (León, 2005; Ibarra, 2010).

\section{c. La "mala administración de justicia"}

Una acusación frecuentemente estampada en los juicios, fue la hecha en contra de los mismos funcionarios judiciales por "negativa de justicia" o "mala administración de justicia", ambas derivadas de problemas distintos, pero que afectaban al mismo sistema. Un ejemplo de ello fue lo ocurrido a José Garcés, quien alegó ser víctima de las arbitrariedades del inspector Vicente Guzmán. Noticiado el gobernador, envió una nota a Guzmán donde le señalaba que el afectado:

"Se ha quejado de despojo contra U[sted] por habérsele quitado de propia autoridad un cavallo rosillo moro que hubo legalmente de Diego Salazar vecino de Tucapel (...). Tal procedimiento -advertía el gobernador al inspector- no es arreglado [a derecho] porque aun cuando fuese el cavallo de U[sted] ha debido intervenir [primero] la autoridad [judicial] para su entrega" 29 .

Otra razón de queja era el largo tiempo de los juicios, lo que implicaba dejar en la cárcel por semanas, meses o años a los procesados, incluso a aquellos que estaban bajo el rótulo de sospechosos. En 1851, el reo Juan

28 "Causa por hurto contra Pedro González y Gilberto Henríquez", Coronel, 30 de noviembre de 1875, f. 4. En: Ibídem.

29 "Oficios enviados por la Gobernación a la Intendencia de Concepción", Santa Juana, 20 de enero de 1851, sin foja. En: Gobernación de Lautaro. 
Manuel Martínez se quejaba ante la justicia debido a que "(...) se cree permaneser mas del tiempo que se llama su delito, sobre el cual no ha sido condenado aun, en mas de diez i siete meses [es decir, casi un año y medio] a qe se halla preso" ${ }^{\prime 3}$. Otros procesos largos, terminaban sentenciando la inocencia de los acusados, mas la prolongación de los mismos juicios llevó en más de una vez a consecuencias indeseadas como el haber afectado la salud de los reos o haber privado durante meses a sus familias de un ingreso monetario regular, toda vez que algunos de ellos alegaban ser el único sostén de sus familias.

En otras oportunidades, se acusó directamente al aparato judicial por no hacer bien su trabajo. Fue el caso del reo José Manuel Ortiz, quien actuó haciendo justicia con sus propias manos hiriendo a otra persona (Eusebio Montes). Cuando el juez sumariante le preguntó qué le llevó a irse a las manos y por qué no dio antes cuenta a la autoridades para que ellas diesen castigo judicial a quien terminó herido, el reo respondió: "(...) que no se querello a las justicias porque no le dan oído a sus reclamos i si [hizo] uso de sus manos fue por esta ra[zón]"31. 


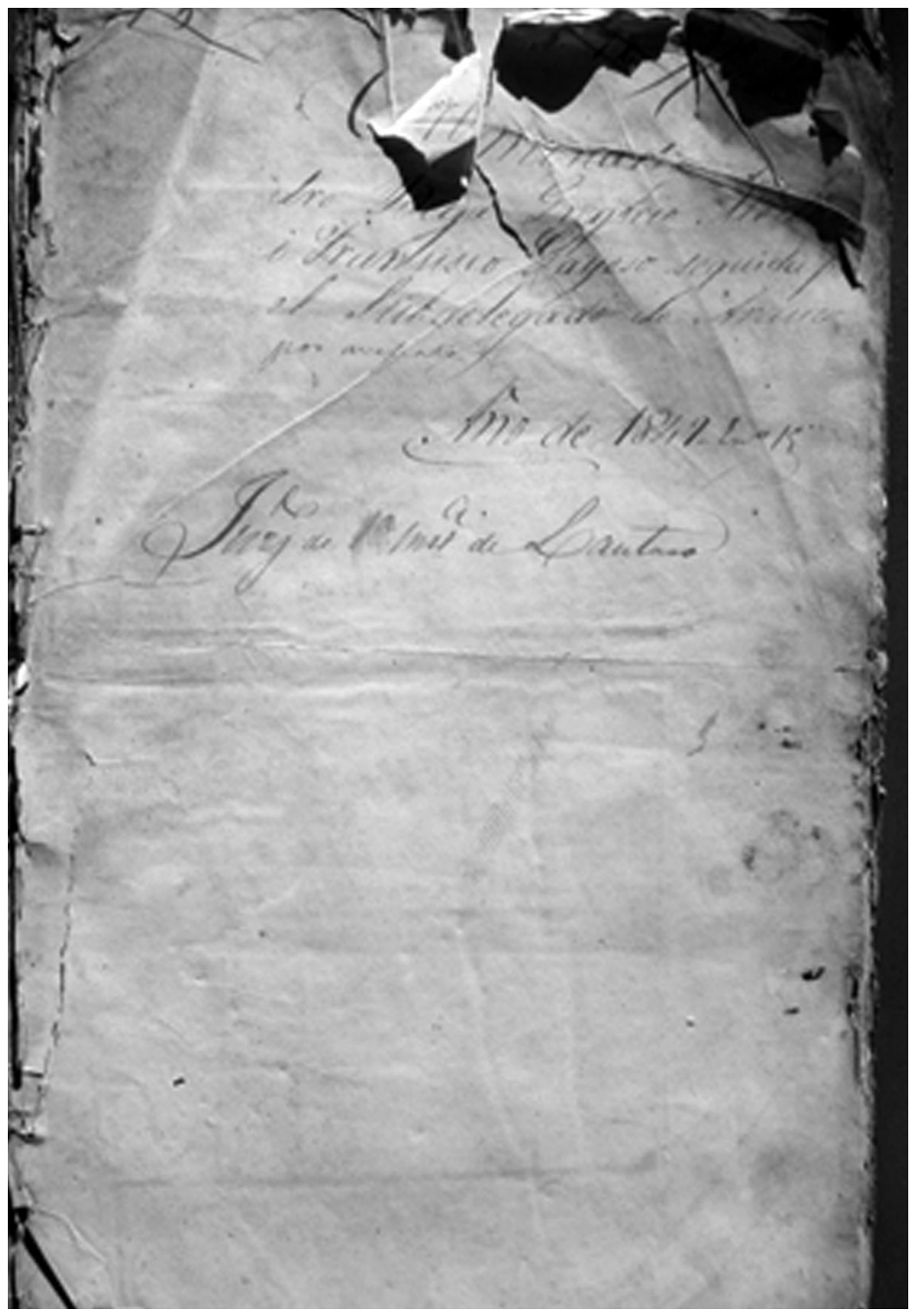

Figura 3 Pieza judicial más antigua del Archivo del Juzgado de Letras de Coronel, fechado el 19 de enero de 1849.

Otro ejemplo de mal proceder de las autoridades judiciales fue el caso de Ambrosio Vergara, quien en 1868 señalaba que a fines de mayo o junio de 1867 su hija Eduviges Vergara había sido raptada y que, según noticias que él obtuvo personalmente, estaba en un lugar llamado Paso Hondo siendo el raptor el ex-subdelegado de Culenco Victorio Medina, quien era amigo del 
subdelegado vigente al tiempo de la denuncia. Al respecto, el abogado del demandante alegaba que:

"Han trascurrido algunos meses sin hacer muchas pezquisas mientras tanto el criminal ha gozado i goza en su delito impunemente i aun se ha paseado públicamente con dicha menor a vista del Subdelegado de Culenco don José Chavez, en casa de N. Idalgo de la misma subdelegación" ${ }^{32}$.

La acusación, pese a la gravedad, no condujo a sentencia.

Otro ejemplo se dio en 1869 cuando dos abogados de Coronel (Plácido Concha y Pedro Delgado) se vieron involucrados en una querella mutua por injurias. Concha acusaba a su colega Delgado de insultarlo continuamente tratándolo como una persona de "pocas luces" (poco inteligente), acusándolo de perseguir a los reos y de encauzarlos judicialmente atendiendo a odiosidades y venganzas personales. Estos cargos, graves por su naturaleza, llevaron a Concha a entablar una querella criminal pidiendo una condena de un año de presidio urbano para su colega. El conflicto se extendió entre el 11 de marzo y el 16 de agosto de 1869, y terminó con una reconciliación obligatoria (previa absolución de Pedro Delgado) y un emplazamiento a "ambas partes que en lo sucesivo se guarden el respeto debido al apercibimiento de una multa de cincuenta pesos a veneficio fiscal que se impondrá al que infrinja el mandato" ${ }^{33}$. Queda claro, finalmente, que si participantes de la administración de justicia no eran capaces de superar sus diferencias ¿con qué moral se exigía a los representados cumplir los mandatos de la ley?

\section{d. El contexto: las tierras de la Baja Frontera}

El hecho de que el área de estudio fuese el departamento de Lautaro, implica necesariamente mencionar su pertenencia al territorio de la Baja Frontera. Esto significaba en la práctica una lucha constante entre la tradición y la modernidad ${ }^{34}$, entre las leyes consuetudinarias y las leyes estatales, entre

32 "Causa por rapto, contra Victorio Medina", Santa Juana, 10 de febrero de 1868, f. 6 y ss. En: Ibídem.

33 "Causa por injurias contra Pedro Delgado", Coronel, 16 de agosto de 1869, p. 13 y $13 \mathrm{v}$. En: Ibídem.

34 Quien trabaja el tema en la zona de la Araucanía es Leonardo León (2002) en su artículo, "La transgresión mestiza en la vida cotidiana de la Araucanía, 1880-1900", en Revista de Historia Social y de las Mentalidades, №6, pp. 67-107. También en su artículo (2007), "Tradición y Modernidad: vida cotidiana en la Araucanía (1900-1935)", en Historia № 40, Pontificia Universidad Católica de Chile, pp. 333-378. En términos nacionales es importante ver el libro de Luis Ortega (2006), Chile en ruta al capitalismo. 
el trabajo tradicional del campo y el proletarizado generado por el desarrollo de la explotación carbonífera.

Agréguese a lo anterior, el ambiente de tensión constante ante la amenaza de enfrentamientos con los mapuches de la zona de Arauco y Nacimiento (departamentos vecinos al de Lautaro), en especial en los convulsos años que van entre 1851 y 1859. Ello terminó alterando el normal funcionamiento del aparato judicial volviéndolo, a ratos, casi anárquico de no ser por las autoridades locales que tomaron el control de una situación que pareció completamente desbordada como, por ejemplo, tras el incendio de la villa de Negrete o tras el alzamiento de la guardia cívica de Arauco en 1859, antesala de la Guerra Civil en dicha zona (Guevara, 1903: 175-256).

Cabe destacar que el desarrollo de la industria del carbón en Coronel y Lota, trajo consigo consecuencias que desde el punto de vista judicial surgiera un antes y un después en el departamento de Lautaro. Desde entonces, las denuncias por injurias aumentaron, los informes que detallan alzamientos (en especial en fiestas patrias como consecuencia del consumo de alcohol) fueron una constante, el número de causas por heridas subió, los hurtos y robos también aumentaron, mientras que también experimentaron un incremento los desacatos a la autoridad, todo ello concentrado cada vez más en las villas minero-carboníferas, aun cuando -vale destacarlo- la estadística de delitos seguía siendo encabezada por el de abigeato.

Un juicio que evidencia claramente el estilo de vida de la vida fronteriza es el seguido contra dos campesinos que hirieron a un policía y a un inspector (que actuaba también como un juez rural) en una fiesta que acompañaba una carrera de caballos, testimonio que merece transcribirse íntegramente:

"El domingo tres del corriente [mes de abril de 1864], hallándose el declarante [José Riquelme] con una ramada de venta en la loma de don Elizardo Teran donde se corria una carrera de caballos sucede que en la ramada del declarante, Bernardo Navarrete estava cometiendo desordenes, llamó Dionisio Guzmán al vijilante Victorino Zapata para que evitara el desorden que cometía Navarrete, el vijilante le pegó una topada que lo votó con caballo i el vijilante se retiró. Mas despues se levanto Navarrete i vio al vijilante al que se encontró i lo bajó caballo abajo [sic] i llegaron a la ramada (...) i alli siguieron peleando teniendo al vijilante en el suelo; en este acto se aproxima Bernardino Garrido diciendole a Navarrete que le pegara mas al vijilante (...) con un rebenque que andaba trayendo les pegaba a todos de palos para que no se aproximasen a defender al ajente [de] policía, a esto llega el Inspector D. Domingo Leal a defender al vijilante y resulta que Bernardino Garrido lo agarró a palos [a] este sin obedecer al jues, se arroja al vijilante, le quita el sable y con él principia a darle a cuantos 
se aproximaban, principalmente al jues, el cual salio herido como igualmente el vigilante" 35 .

Así se arreglaban las cosas en los campos de la Baja Frontera, claro está con unas botellas demás en el cuerpo. La desobediencia, el desconocimiento de la autoridad judicial y policial, el honor herido, eran causas suficientes para que estos sujetos fronterizos no distinguieran títulos, cargos ni armas al momento de solucionar una afrenta. "La arrogancia de los mestizos -señala Leonardo León- y su disposición agresiva estaban siempre presentes para resolver sus conflictos, en especial cuando se encontraban con extraños" (León, L. 2005: 108).

Otro juicio fue en la misma dirección: "(...) se me ha notisiado del paradero en este partido de Juan Feliz Beloso i de Juana Maria Bermedo autores de un robo hecho al párroco de Colcura (...)", señalaba un subdelegado al juez de primera instancia en 1855. Una vez detenida la mujer implicada, declaró haber estado en ilícita amistad con su cómplice y que cuando el cura salía de misiones ella se iba con su amante a la pieza del sacerdote. ¿Había respeto siquiera por este tipo de autoridad espiritual? ¿Cómo se entienden estos comportamientos? ¿O sencillamente son nuevas evidencias de conductas consideradas normales por la plebe y anormales por la élite? Goicovic señala que:

"Por lo general todos los conflictos que involucran el ejercicio de la violencia, ya sea a través del uso de armas, de la aplicación de la fuerza o de la utilización de un lenguaje agresivo, (...) se analizaban [por la élite] desde una óptica que no consideraba estas acciones como conscientes o fruto de algún tipo de asociatividad social o política, sino que se explicaban y vinculaban a la inconciencia etílica, a los "perversos instintos" de los grupos populares y a la falta de resguardo policial. Asimismo la falta de disciplina de los sectores populares, así como las constantes reincidencias en las mismas faltas (y habitualmente de los mismos perpetradores), se atribuían no a las condiciones paupérrimas en las que éstos vivían, sino a la deficiencia y carencia en los dispositivos de control social, enfatizando aquellos de carácter represivo y policial por sobre los vinculados a la educación pública o a las supletorias del gobierno local o del Estado (Goicovic, 2008: 7-8).

Refiriéndose a los poblados minero-carboníferos, Luis Ortega identifica a parte de los sujetos que comenzaron a llenar las plazas de trabajo ofrecidas

35 Archivo Judicial de Coronel, "Causa por heridas, contra Bernardo Navarrete y Bernardino Garrido", Santa Juana, 5 de abril de 1864, f. 1v. 
por los minerales $y$, por ende, a habitar en estas localidades en conjunto con aquellos que sólo buscaban mejorar ese huidizo progreso del que tanto se hablaba y que el campo les negaba. Según Ortega, en torno a los poblados minero-carboníferos se constituyó un mundo de seres expectantes:

"Algunos fueron bandoleros rurales (...). Otros fueron campesinos y los demás vagos no errantes, habitantes de los extramuros de las villas, pueblos y ciudades, pero siempre prontos a concurrir a aquellos y sus bodegones, chinganas, ramadas, tabernas, canchas de bolos y reñideros de gallos. Todos fueron proclives a la bebida, pendencieros y propensos a resolver sus diferencias (...) de acuerdo con su propio estilo de vida, en el que el recurso a la violencia física era algo natural" (Ortega, 1992: 102-103).

En este ambiente, donde las cárceles exhibían una constante inseguridad, donde los vigilantes y la policía eran ineficientes e insuficientes, y donde los integrantes del aparato judicial no lograban -en ocasiones- superar sus diferencias (mimetizándose con la vida fronteriza en la cual cotidianamente se vieron envueltos), pueden comprenderse mejor las actitudes de los criminales que actuaron en la Baja Frontera costera que envolvía al departamento de Lautaro. Súmese a lo anterior la heterogénea conformación étnica y social, conformada por mapuche-lafquenches, chilenos, mestizos chileno-mapuches (al decir de Leonardo León) y extranjeros, miembros de la élite política, empresarios, obreros y campesinos.

Cabe resaltar que las acciones definidas como "delitos" por la justicia chilena, muchas veces no eran entendidas así por los mismos habitantes de estas tierras, muchos de ellos no aceptaban la categoría de crimen dada a sus actuaciones, pues la consideraban una denominación de origen lejano (estatal), lo que dificultó a la institucionalidad judicial aplicar leyes y decretos emanados en los salones del Congreso Nacional. No obstante, los nuevos tribunales y juzgados de la Baja Frontera eran cada vez más conscientes de que en esta área geográfica se enfrentarían al muro de la tradición atávica contra el cual siguió luchando hasta bien entrado el siglo XX. No está de más recordar que el término Frontera especifica un límite real entre el mundo chileno y el mundo mapuche y más intangible si lo pensamos en términos de la separación entre "civilización y barbarie" (al decir de John Mackay hacia 1845 en su diario de viaje). Es la evidencia del distanciamiento entre la ley de origen estatal y la tradición de las normas y costumbres consuetudinarias que estos sujetos, en su mayor parte populares, estaban acostumbrados a respetar. Las leyes del Estado de Chile debieron esperar mucho más para ser respetadas en las tierras del sur del río Biobío en forma más masiva, ya que en definitiva en estos territorios del antiguo lafquenmapu el Estado chileno en el período aquí analizado nunca pudo "sentar bien sus reales". 


\section{Conclusiones}

La Baja Frontera en la cual nos hemos centrado, particularmente en el departamento de Lautaro - de una extensión no despreciable, correspondiendo a las actuales comunas de San Pedro de la Paz, Coronel, Lota y Santa Juanafue testigo de complejos procesos que involucraron tanto modernidad como tradición, ejemplificados en la instalación de las primeras minas de carbón en la costa (Coronel y Lota) de una parte, así como en la mantención de un estilo de vida de tipo fronterizo, es decir, conforme a las leyes consuetudinarias de los habitantes de la frontera, de otra.

Ello llevó a que el Poder Judicial y su institucionalidad trataran de frenar la comisión de delitos que variaron en su gravedad, al menos en cuanto a las causas que llegaron a las salas de los tribunales fronterizos, ya que es seguro que muchos otros delitos se desarrollaron en total impunidad, fenómeno explicable debido a que la presencia real del Estado en esta zona y en las fechas que abarcó el estudio (1849 - 1869) era bastante débil, como ha quedado demostrado con los testimonios aquí descritos. Esta circunstancia impidió hacer valer con todo su peso la autoridad estatal en estas tierras, situación heredada a las generaciones posteriores caracterizadas por un estilo de vida que convivió cotidianamente con la transgresión a las normas y leyes, situación que se mantuvo hasta principios del siglo XX.

Entre las causas que hemos destacado como facilitadores del desarrollo de la criminalidad en esta área, estaban la mala calidad de las cárceles y la ineficacia de la policía encargada de cuidar a los mismos reos que de una u otra manera aportaban a la comisión de los delitos. Estos se agravaban toda vez que incluso los mismos encargados del orden y seguridad contribuían a veces a la inseguridad cuando por distintas causales dejaban en libertad a los presos que vigilaban. Recapturar era algo difícil en una zona de geografía complicada, con ríos, bosques y la Cordillera de Nahuelbuta, seguro refugio para los infractores de la ley.

También hemos visto que los integrantes del mismo aparato estatal, tales como abogados y jueces, infringían las normas de comportamiento legal, dando un poco ejemplificador legado a los gobernados. Pero sin lugar a dudas fue la cultura fronteriza, transgresora, su desconocimiento de las leyes estatales y de sus autoridades, además del peso de la costumbre, lo que más dificultó la presencia del Estado en cuanto obediencia a las instituciones judiciales se trata.

En todo caso cabe señalar que la judicialización de estas tierras, fue sólo una de las aristas en el camino seguido por el Estado de Chile para hacer valer su presencia en esta zona donde el mestizaje no sólo se redujo a lo 
interétnico, sino que se extendió a lo cultural, lo cual permite entender los comportamientos contestatarios de estas personas que protagonizaron esta interesante etapa de nuestra historia fronteriza.

\section{Referencias bibliográficas}

\section{Fuentes primarias}

\section{a. Documentales}

Archivo Judicial de Coronel, 1849 - 1869.

Archivo Gobernación de Lautaro, 1849 - 1869.

\section{b. Impresos}

Oficina de Estadística (1850). Repertorio nacional formado por la Oficina de Estadística en conformidad del artículo 12 de la lei de 17 de setiembre de 1847, Imprenta del Progreso, Plaza de la Independencia, Santiago de Chile.

Oficina Central de Estadísticas (1866). Censo Jeneral de la República de Chile levantado el 19 de abril de 1865, Imprenta Nacional, Santiago de Chile.

\section{Fuentes secundarias}

BRITO, A. y C. Vivallos (2010). "Inmigración y sectores populares en las minas de carbón de Lota y Coronel (Chile, 1850-1900)", en Atenea, № 501, p. 53-71.

FOERSTER, R. (2008). "Los procesos de constitución de la propiedad en la frontera norte de la Araucanía: sus efectos esperados y no esperados en el imaginario y en la estructura de poder", en Cuadernos de Historia, № 28, p. 7-35.

GODOY, M. (2003). "Fiesta, borrachera y violencia entre los mineros del norte chico (1840-1900)", en Revista de Historia Social y de las Mentalidades, № 7 , p. 81-117.

GOICOVIC, I. (2008). "Construcciones discursivas y mecanismos de Disciplinamiento social. Angol 1900-1920", en XIV Jornadas de Historia Regional de Chile, PUCV, Viña del Mar (inédito).

GREZ, S. (2007). De la "regeneración del pueblo" a la huelga general: Génesis y evolución histórica del movimiento popular en Chile (1810-1890). Santiago de Chile: RIL.

GUEVARA, T. (1902). Historia de la civilización de la Araucanía. Vol. 3. Santiago de Chile: Editorial Universo. 
IBARRA, C. (2010). Criminalidad popular en el departamento de Lautaro, 1849 - 1879. Tesis para optar al grado de Magíster en Historia, mención Historia de Chile, Universidad de Chile. Versión on line: http://www.tesis.uchile.cl/tesis/ uchile/2010/fi-ibarra_c/html/index-frames.html

LAGOS, A. (1999). Recopilación de antecedentes geográficos, históricos, económicos y culturales de Coronel. Concepción: Ícaro.

LEÓN LEÓN, M. (2001). "Criminalidad y prisión en la Araucanía chilena, 18521911", en Revista de Historia Indígena, № 5, p. 135-160.

LEÓN, L. (2002). "La transgresión mestiza en la vida cotidiana de la Araucanía, 1880-1900", en Revista de Historia Social y de las Mentalidades, №6, p. 67-107.

LEÓN, L. (2005). Araucanía: la violencia mestiza y el mito de la pacificación, 1880-1900. Santiago de Chile: Universidad ARCIS, Escuela de Historia y Ciencias Sociales.

LEÓN, L. (2007). "Tradición y Modernidad: vida cotidiana en la Araucanía (19001935)", en Historia, № 40, Pontificia Universidad Católica de Chile, p. 333-378.

MAZZEI, L. (1999). "Matías Cousiño antes de Lota. Formación y proyecciones de un empresario minero", en Atenea, № 480, p. 85-128.

MINISTERIO DEL INTERIOR (1927). "Decreto con fuerza de ley No 8.582. Decreto que fija la nueva división territorial de la República". Biblioteca del Congreso Nacional, versión en línea: http://bcn.cl/fvkr

ORTEGA, L. (1992). "La frontera carbonífera", en Mapocho, № 31. Santiago: DIBAM, p. 131-148.

ORTEGA, L. (2005). Chile en ruta al capitalismo, cambio, euforia y depresión 1850-1880. Santiago de Chile: Ediciones CIDBA, DIBAM.

PINTO, Jorge (1985). "El bandolerismo en la frontera, 1880 - 1920. Una aproximación al tema", en: Pinto, J. y Villalobos, S. (compiladores). Araucanía, temas de historia fronteriza. Temuco: Ediciones Universidad de la Frontera, pp. 101-122.

PINTO, Julio; Salazar, G. (1999). Historia contemporánea de Chile, vol. II. Santiago de Chile: LOM.

SALAZAR, G. (2000). Labradores, peones y proletarios. Santiago de Chile: LOM. 